\section{Anaesthetic considerations in progressive familial intrahepatic cholestasis (Byler's disease)}

Gerhard Müller MD, Francis Veyckemans MD, Marianne Carlier MD, Luc J. Van Obbergh MD, Marc De Kock MD, Etienne M. Sokal MD PhD, * Jean-Bernard Otte MD $\dagger$
Progressive familial intrahepatic cholestasis (PFIC) or Byler's disease is one of the most common forms of intrahepatic cholestasis of metabolic and genetic origin. Affected children progress to terminal cirrhosis before adulthood and at present the only curative treatment of PFIC is onthotopic liver transplantation (OLT). We present a retrospective review of 40 general anaesthetics administered in our haspital to 22 patients with PFIC undergoing various procedures. The clinical features of PFIC and the anaesthetic implications of chronic cholestasis in children (malnutrition, cirrhosis, portal hypertension, chronic hypoxaemia) are reviewed.

La cholestase intrahépatique progressive familiale (PFIC) ou maladie de Byler est une des formes les plus courantes de cholestase intrahépatique de cause métabolique et génétique. Les enfants qui en sont atteints évoluent vers la cirrhose terminale avant l'âge adulte. Jusqu'à présent, le seul traitement curatif de la PFIC est la transplantation hépatique. Nous avons revu de manière rétrospective 40 anesthésies générales administrées dans notre hôpital à 22 enfants souffrant de PFIC. Les différentes présentations cliniques de la PFIC et les implications anesthésiques de la cholestase chronique de l'enfant (malnutrition, cirrhose, hypertension portale, hypoxémie chronique) sont présentées.

\section{Key words}

ANAESTHESIA: paediatric, inhalation, intravenous; LIVER: cholestasis, cirrhosis, hypoxaemia; SYNDROMES: Byler's disease, progressive familial intrahepatic cholestasis.

From the Departments of Anaesthesiology, Paediatric Gastroenterology* and Paediatric Surgery $\dagger$, Catholic University of Louvain Medical School, Cliniques Universitaires St Luc, Avenue Hippocrate 10, 1200 Brussels, Belgium.

Address correspondence to: Dr. F. Veyckemans, Department of Anaesthesiology, Cliniques Universitaires St Luc, Avenue Hippocrate 10-1821, B-1200 Brussels, Belgium.

Accepted for publication 20th July, 1995.
Although rare, Progressive Familial Intrahepatic Cholestasis (PFIC) or Byler's disease is one of the most common forms of intrahepatic cholestasis of metabolic and genetic origin. ${ }^{1,2}$ Patients suffer from cholestasis and marked pruritus within the first months of life, and progress to endstage cirrhosis before adulthood. ${ }^{3}$ The precise metabolic defect responsible for this autosomal recessive disorder is still unknown. ${ }^{2}$ Because of their liver disease, these children are submitted to several investigational and/or therapeutic procedures performed under general anaesthesia such as endoscopies, liver biopsies, biliary surgery and eventually liver transplantation. ${ }^{4,5}$ We carried out a retrospective review of the anaesthetic records of 22 children with PFIC who underwent such procedures in our institution. The anaesthetic implications of the various clinical presentations of this disease will be discussed.

\section{Review of the cases}

We reviewed the anaesthetic and medical records of all the children with PFIC admitted to our hospital from 1985 to September 1994 to undergo a procedure requiring an anaesthetic. A total of $\mathbf{4 0}$ general anaesthetics were administered to 22 children. The following procedures were performed: six liver biopsies, six liver biopsies combined with an oesogastroscopy, 11 oesogastroscopies, three laparotomies, two bile duct diversion procedures (see below), two radiological explorations and 16 orthotopic liver transplantations (OLT). No other surgical procedures were performed on children with PFIC in our hospital during that period.

There were 13 boys and nine girls. Their ages and weights at the time of first anaesthetic in our hospital varied from 2 to 168 months (mean $48.5 \pm 44.5 \mathrm{SD}$ ) and from 4.3 to $27 \mathrm{~kg}$ (mean $13.4 \pm 6.6$ ), respectively. A family history of cholestasis was recorded in one-third of the cases. All were subicteric or icteric (range of plasma total bilinubin concentration: from subnormal to 45 $\left.\mathrm{mg} \cdot \mathrm{dl}^{-1}\left(=769 \mu \mathrm{mol} \cdot \mathrm{L}^{-1}\right)\right), 85 \%$ of them complained of pruritus and six had skin excoriations. None had chole- 
lithiasis. A history of frequent spontaneous epistaxis in the absence of biological coagulopathy was present in five cases. Of these, one presented with complete synechiae of one nostril and another had a history of bleeding requiring blood transfusion after tonsillectomy at another hospital. Prothrombin times varied from 15 to $100 \%$ of control; plasma total cholesterol concentration was normal $\left(150-250 \mathrm{mg} \cdot \mathrm{dl}^{-1}\right)$ in all patients and plasma gamma glutamyl transferase (GGT) concentration was normal $\left(<45 \mathrm{mg} \cdot \mathrm{dL}^{-1}\right)$ in all but three. Of the $16 \mathrm{pa}$ tients who had a radiological examination of long bones, ten presented diffuse osteopenia ( $<$ P5 for age), two had discrete signs of osteomalacia and only one had evidence of rickets. All patients undergoing pretransplant evaluation were systemically screened for hypoxaemia while breathing room air, either with blood gas analysis or with pulse oximetry: only one (age 60 months) was found to be hypoxaemic $\left(\mathrm{PaO}_{2}: 54 \mathrm{mmHg}\right.$ at $\left.\mathrm{FIO}_{2} 21 \%\right)$ but this was not investigated further; none of the patients in whom intraoperative arterial blood gases were analyzed presented an abnormal alveoloarterial $\mathrm{PO}_{2}$ gradient. These same patients also had an echocardiographic examination: the most common finding was an enlarged left atrium, which was interpreted as a sign of increased cardiac output; a small atrial septal defect was found in one child. Neurological examination was normal in all cases but two children had a history of seizures. Two patients were admitted with acute liver failure and underwent urgent OLT.

Most patients did not receive premedication; otherwise, only atropine im was administered. An inhalational induction technique was used 16 times (12 halothane, four isoflurane) while intravenous drugs were used 24 times (thiopentone two, etomidate seven, and propofol 15 times, respectively). Cricoïd pressure was applied until tracheal intubation was achieved in emergency cases or if ascites was present. Isoflurane was given for maintenance of anaesthesia if the procedure lasted more than a few $\mathrm{min}$ utes. Succinylcholine, pancuronium or atracurium were used when paralysis was necessary. Fentanyl was used 13 times, alfentanil 14 and sufentanil four times (Table I). One child was sedated for percutaneous liver biopsy with the combination of droperidol and diazepam administered by the radiologist. No untoward reaction (prolonged duration of action or postanaesthetic clinical deterioration of liver function) to any agent was observed. Although most of these children were small for their age, when an uncuffed endotracheal tube was inserted, the size which allowed an air leak between 20 and $25 \mathrm{~cm}$ $\mathrm{H}_{2} \mathrm{O}$ did not differ from the rule (ID $=[16+$ age in years] $\left.\cdot 4^{-1}\right)$.

A thoracic epidural catheter was inserted in one patient
TABLE I Distribution of the anaesthetic agents used

\begin{tabular}{lcc}
\hline Name & Induction & Maintenance \\
\hline Halothane & 12 & 0 \\
Isoflurane & 4 & 32 \\
Thiopentone & 2 & 0 \\
Etomidate & 7 & 0 \\
Propofol & 15 & 0 \\
Succinylcholine & 8 & 0 \\
Atracurium & 6 & 2 \\
Pancuronium & 0 & 16 \\
Alfentanil & 13 & 1 \\
Fentanyl & 6 & 13 \\
Sufentanil & 1 & 4 \\
\hline
\end{tabular}

and was used successfully per- and postoperatively. In another, a continuous $i v$ infusion of morphine (15 to 20 $\mu \mathrm{g} \cdot \mathrm{kg}^{-1} \cdot \mathrm{hr}^{-1}$ ) was administered during the first $48 \mathrm{hr}$ after surgery in the paediatric surgical ward. Most patients who underwent OLT received a continuous infusion of fentanyl iv during their early postoperative stay in the Paediatric Intensive Care Unit. Percutaneous liver biopsies were performed with ultrasound control in the paediatric radiology suite: deep sedation was achieved with alfentanil and propofol administered by an anaesthetist in addition to a local anaesthetic infiltration performed by the radiologist or paediatrician.

Sixteen patients underwent OLT: their haemodynamic tolerance and metabolic responses to the different stages of surgery were similar to those we observed in children with end-stage biliary cirrhosis caused by biliary atresia. ${ }^{6}$ However, six of the first ten patients with PFIC undergoing OLT presented with major deficiencies in vitamin $\mathrm{K}$-dependent clotting factors and fibrinolysis and were massively transfused peroperatively with factor IX cryoprecipitate, fresh frozen plasma, blood and platelets. They received a mean $\pm S D$ of $319 \pm 158 \mathrm{ml} \cdot \mathrm{kg}^{-1}$ of blood + plasma and $0.4 \pm 0.3$ units of platelets $\cdot \mathrm{kg}^{-1}$ vs 150 $\pm 72 \mathrm{ml} \cdot \mathrm{kg}^{-1}$ and no platelets for the others. Fortunately, this clinical condition has progressively disappeared due to the combination of better pretransplant nutritional support, earlier indication for transplantation and an improved surgical technique.

One boy $(22 \mathrm{mo}, 9.9 \mathrm{~kg})$ died with multiple organ failure two months after undergoing a partial cutaneous biliary diversion procedure. His early postoperative period was complicated by high fever $\left(39^{\circ} \mathrm{C}\right)$ of unknown origin and the massive production of ascites $(>2 \mathrm{~L}$ per day) which could not be controlled despite medical treatment with diuretics, salt-poor albumin and paracentesis. Numerous investigations (among which two laparotomies 
and the angiographic exploration of the supra hepatic vessels) failed to reveal any extrahepatic cause of this acute postoperative decompensation of apparently stable PFIC (prothrombin time $100 \%$ of control and total bilirubin $284 \mu \mathrm{mol} \cdot \mathrm{L}^{-1}$ on admission).

\section{Discussion}

\section{The disease}

First described by Clayton et al..$^{7}$ in 1965 in a family of six Amish children, PFIC or Byler's disease is an autosomal recessive condition characterized by intrahepatic cholestasis and progressive changes to fibrosis and finally cirrhosis that leads to death during childhood. The exact mechanism of the disease is still unknown. Extremely low amounts of bile acids are detected in the bile of patients with PFIC despite their considerable accumulation in the serum, suggesting an inborn error of the biliary secretion of primary bile acids. ${ }^{8}$ Clinically, the first symptoms of PFIC are episodes of cholestasis (pale stools, dark urine and pruritus) starting during the first year of life. ${ }^{1-3,9}$ Persistent cholestatic jaundice usually develops during the following two to three years leading to other clinical manifestations such as pruritus, the severity of which is often out of proportion to the degree of hyperbilinubinaemia, ${ }^{9}$ failure to thrive, gallstones, acute or chronic pancreatitis, digital clubbing. ... 1,7 Moreover, Whitington et al. report a high incidence of wheezing and of recurrent epistaxis in the absence of coagulopathy in their series. ${ }^{9}$ The disease usually progresses by successive episodes of acute cholestasis which can be triggered by an intercurrent infection. ${ }^{3}$ Signs related to malabsorption and malnutrition such as rickets, osteomalacia, a vitamin $\mathbf{E}$ deficiency-associated neurological syndrome (areflexia, ataxia) ${ }^{1}$ and developmental delay appear if parenteral vitamins and a special diet are not provided. ${ }^{10}$ The early introduction of parenteral fatsoluble vitamins (A, D, E, K) explains the absence of gross neurological abnormalities and the low incidence of rickets and osteomalacia in our series, although osteopenia was common. Chronic hepatic dysfunction progressively results in portal hypertension and consequently produces a state of hyperdynamic circulation, splenomegaly with hypersplenism, low plasma albumin and ascites. Hypoxaemia is likely to occur once portal hypertension is present " and may then be caused by abdominal distension, ventilation-perfusion imbalance, pulmonary infection or pulmonary arteriovenous shunting. To date, hypoxaemia has not been documented in children with PFIC but the presence of digital clubbing in the initial descriptions of the disease ${ }^{1,2.7}$ gives support to the possible occurrence of hypoxaemia in these patients ... Bleeding oesophageal varices, ascites refractory to medical treatment and/or acute liver failure are the usual signs of the terminal stage of the disease.

Early in the disease, liver biopsy generally shows an aspecific pattern of cholestasis with normal biliary ducts; later, it shows various degrees of fibrosis and, finally, cirrhosis. The extrahepatic bile ducts are normal as demonstrated by ultrasound, retrograde cholangiography or laparotomy (some neonates or infants with PFIC unfortunately undergo a laparotomy with a presumptive diagnosis of biliary atresia).

The diagnosis of PFIC is based on the exclusion of the other familial causes of intrahepatic cholestasis (see below) and on the presence of normal plasma GGT and cholesterol concentrations. ${ }^{2,9}$ Children with ArterioHepatic Dysplasia (Alagille's syndrome) present in infancy or early childhood with cholestasis caused by paucity of intrahepatic bile ducts. They also present with a particular facies (triangular face with broad forehead, moderate hypertelorism and flattened nose), cardiac disease (stenosis of the peripheral pulmonary arteries, either isolated or associated with other complex abnormalities), bone abnormalities ("butterfly"-like vertebral arch defect) and an asymptomatic embryological remnant in the anterior chamber of the eye (called posterior embryotoxon). ${ }^{2}$ Their plasma GGT and cholesterol concentrations are very high and they often demonstrate multiple xanthomas. Benign recurrent intrahepatic cholestasis usually presents as recurrent episodes of cholestasis: plasma cholesterol concentrations are elevated during these attacks of cholestasis, but GGT levels may remain normal. ${ }^{2,12}$ Despite years of repeated episodes of cholestasis, this disorder does not cause cirrhosis. Primary bile acid synthesis defects, such as the recently described deficiency in 3 beta-hydroxy-C27-steroid dehydrogenase/isomerase, ${ }^{13}$ present in children with clinical features similar to PFIC but with no pruritus and normal serum bile acid concentration. Establishing the correct diagnosis is important because bile acid therapy can normalize liver function in these children.

At present, the only curative treatment of PFIC is OLT. ${ }^{4,5}$ Medical treatment is symptomatic: cholestyramin $e^{1,7,14}$ has some favourable effects on pruritus but does not improve clinical status; phenobarbitone is sometimes prescribed to reduce bilirubin concentration. ${ }^{1}$ High-dose ursodeoxycholic acid gives good results in some patients. ${ }^{9}$ Different surgical techniques have been proposed: internal biliary drainage is not effective but partial cutaneous biliary diversion ${ }^{15}$ seems to relieve pruritus while normalizing serum bilirubin concentration and, in patients with no fibrosis at the time of operation, to reverse histological signs of cholestasis. Cholecystectomy should be avoided 
in patients with PFIC because partial cutaneous biliary diversion involves anastomosing the dome of the gallbladder to the skin via a short jejunal conduit. ${ }^{15}$

\section{Preoperative evaluation}

Children with PFIC may present to the anaesthetist with a wide spectrum of clinical conditions ranging from mild cholestatic jaundice with normal liver function to terminal liver failure, or in emergency with bleeding oesophageal varices. In addition to the usual paediatric clinical examination, the hepatic function and nutritional status of the child should be carefully evaluated (Table II). As hypoxaemia is likely to occur and cyanosis is not easily detected in severely jaundiced children, we suggest that all patients should be screened systematically for hypoxaemia. The measurement of arterial haemoglobin oxygen saturation $\left(\mathrm{SpO}_{2}\right)$ with a pulse oximeter is not affected by hyperbilirubinaemia ${ }^{16}$ and direct blood gas analysis is thus not necessary if $\mathrm{SpO}_{2}$ is $>90 \%$. If hypoxaemia is present, contrast-enhanced echocardiography and/or pulmonary scintiscan will allow differentiation of pulmonary arteriovenous shunting from hypoventilation caused by ascites or a pulmonary disease. ${ }^{11}$ Moreover, echocardiography will allow the early diagnosis of pulmonary hypertension, another possible complication of portal hypertension. ${ }^{17}$ Hypoxaemia caused by pulmonary arteriovenous shunting is usually poorly improved by increasing $\mathrm{FrO}_{2}$ but is reversible after successful OLT and is thus nowadays an indication for it. ${ }^{5,11}$

Regarding anaesthetic management, the use of invasive monitoring (arterial and central venous lines) in addition to pulse oximetry, capnography, NIBP, ECG, and temperature, should be adapted to the child's clinical condition and to the importance of the procedure. During controlled ventilation, care should be taken to avoid high airway pressures and hypocarbia because both reduce hepatic (arterial and portal) blood flow. ${ }^{18}$ Anaesthetic agents with no or minimal hepatotoxicity should be used to avoid deterioration of liver function.

\section{Anaesthetics: inhalational}

Up to now, isoflurane has been the inhalational agent of choice in case of liver disease. It decreases total hepatic blood flow only slightly because it increases arterial hepatic blood flow. ${ }^{18,19}$ Although halothane decreases total hepatic blood flow the most, this does not appear during short-lasting ( $<30 \mathrm{~min}$ ) administration. ${ }^{20}$ Moreover, halothane has been used in a series of children with cholestatic jaundice without liver function deterioration. ${ }^{21}$ Therefore, we do not hesitate to use halothane for induction of anaesthesia in infants and small children in whom venous access is not easy to establish, thus avoiding
TABLE II Suggested preoperative evaluation in PFIC

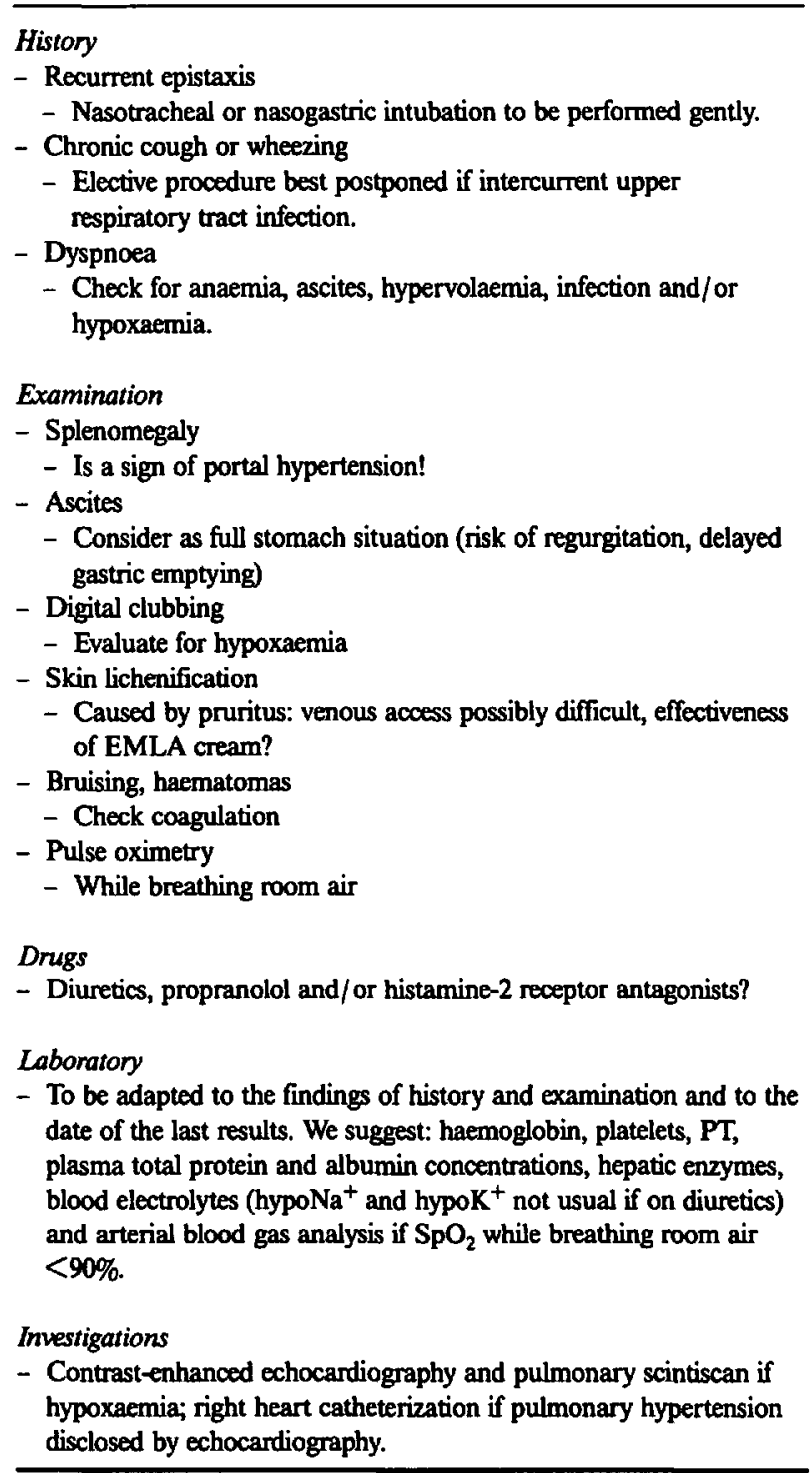

the possible respiratory problems encountered during induction with isoflurane. ${ }^{22}$ Sevoflurane for induction and maintenance of anaesthesia or desflurane for maintenance may be the inhalational agents of choice in the near future because they do not appear to have any hepatic toxicity and their effects on hepatic blood flow are similar to those of isoflurane. ${ }^{23,24}$

\section{Anaesthetics: intravenous}

In patients with liver disease, the metabolism and elimination of intravenous agents are influenced by various factors such as reduced hepatic blood flow, porto-systemic shunting, decreased hepatic enzymatic activity, alteration 
of plasma protein binding and concurrent medical treatment (e.g., diuretics). The relative importance of each factor depends upon the hepatic extraction ratio of the drug considered: high extraction drugs (e.g., lidocaine, morphine, ketamine) depend on hepatic blood flow, while low extraction drugs (e.g., diazepam) depend on enzymatic activity. ${ }^{25}$ Moreover, alterations in drug disposition and elimination may be, in part, dependent on the cause of liver dysfunction: e.g., primary biliary cirrhosis affects mainly the periportal regions and thus has little effect on drug metabolism, whereas alcoholic cirrhosis affects the perilobular regions and may therefore be associated with reduced oxidative metabolism. ${ }^{26}$ On the other hand, although the liver plays the major role in drug metabolism, drug metabolizing enzymes (e.g., glucuronyl transferases) are also present in other tissues (kidney, lung, gut wall ... ) and may be responsible for some extrahepatic metabolism. ${ }^{27,28}$ Moreover, in vitro studies with normal hepatic microsomes have shown that an anaesthetic agent may interfere with the hepatic elimination of another concomittantly used agent. ${ }^{29}$ Last, most human studies concerning the pharmacokinetic consequences of liver disease consider adult patients with compensated alcoholic cirrhosis and receiving a single bolus dose of the drug studied. It is difficult to draw clinically valid conclusions from these studies because the classic pharmacokinetic variables reported (half-lives, clearance, etc. ...) neither predict the rate of clinical recovery following drug administration nor consider pharmacodynamic factors which may modify the patient's response. ${ }^{30}$

The main effects of cirrhosis on the pharmacokinetic behaviour of $i v$ induction agents and the effects of these agents on liver blood flow are summarized in Table III. Fortunately, the duration of action of a single dose of these agents is determined by redistribution from the brain to poorly vascularized tissues rather than by metabolism. However, hypoalbuminaemia decreases their protein binding ${ }^{35}$ and may thus increase their pharmacodynamic effects.

The opioid chosen for peroperative analgesia depends upon the anticipated duration of surgery. For short procedures, our first choice is alfentanil which has similar pharmacokinetic behaviour in children with cholestasis as in normal age-matched patients. ${ }^{38}$ For long procedures, we used repeated boluses of fentanyl for the first patients of the series while the last ones received a continuous infusion of sufentanil. In adults with uncomplicated alcoholic cirrhosis, the elimination half-life of a single bolus dose of fentanyl ${ }^{39}$ or sufentanil ${ }^{40}$ is similar to controls. Remifentanil, either in bolus doses (short procedures) or by continuous infusion, might soon become a good choice as it is metabolized by non-specific blood and tissue esterases. ${ }^{41}$ The use of morphine, either in repeated bolus
TABLE III Induction agents

\begin{tabular}{lll}
\hline Drug & Effect of cirrhosis & $\begin{array}{l}\text { Effect on } \\
\text { liver blood flow }\end{array}$ \\
\hline Thiopentone & $\begin{array}{c}\text { Volume of distribution } \\
\text { and elimination half-life; } \\
\text { if low albumin }\end{array}$ & $\begin{array}{c}\text { Transient /in } \\
\text { portal flow }\end{array}$ \\
Propofol & $\begin{array}{c}\text { None if single dose } \\
\text { considerable extra- } \\
\text { hepatic metabolism }\end{array}$ & None \\
Etomidate & $\begin{array}{l}\text { Prolonged elimination } \\
\text { half-life if infusion }\end{array}$ & $?$ \\
Ketamine & $?$ & Controversial \\
\hline
\end{tabular}

TABLE IV Muscle relaxants

\begin{tabular}{|c|c|c|}
\hline Drug & $\begin{array}{l}\text { Effect of } \\
\text { cirrhosis }\end{array}$ & $\begin{array}{l}\text { Clinical } \\
\text { implication }\end{array}$ \\
\hline Succinylcholine & $\begin{array}{l}\text { \Plasma cholinesterase } \\
\text { activity }{ }^{45}\end{array}$ & $\begin{array}{l}\text { /Duration of } \\
\text { action }\end{array}$ \\
\hline Atracurium & None $^{44}$ & None \\
\hline Pancuronium & $/ \mathrm{Vd}$ and $\mathrm{SC}^{46}$ & $\begin{array}{l}\text { Increase 1st dose } \\
\text { /duration of } \\
\text { action }\end{array}$ \\
\hline Vecuronium & $\backslash \mathrm{CL}^{47}$ & $\begin{array}{l}\text { Duration of } \\
\text { action if large } \\
\text { dose }\end{array}$ \\
\hline Mivacurium & $\begin{array}{l}\mathrm{ICl} \text { by \plasma } \\
\text { cholinesterase activity }{ }^{48}\end{array}$ & $\begin{array}{l}\text { /Duration of } \\
\text { action }\end{array}$ \\
\hline Rocuronium & $\begin{array}{l}\text { /VD and /mean residence } \\
\text { time }^{49}\end{array}$ & $\begin{array}{l}\text { /Duration of } \\
\text { action }\end{array}$ \\
\hline
\end{tabular}

$\mathrm{VD}=$ volume of distribution, $\mathrm{Cl}=$ clearance.

doses or by continuous infusion, to provide postoperative analgesia in children with severe liver disease requires careful assessment of its clinical effects by trained nurses using appropriate pain and sedation scores: although a single bolus dose of morphine undergoes rapid glucuronidation even in the presence of severe liver disease, ${ }^{27,42}$ the elimination half-life of its unchanged form is prolonged ${ }^{43}$ and an associated impaired renal function may lead to the accumulation of its active metabolites. ${ }^{42}$

\section{Muscle relaxants}

Neuromuscular function should be monitored with a nerve stimulator in all patients with liver dysfunction due to the pharmacologic problems (Table IV) and the oftenassociated muscle wasting. For curarization of short duration, atracurium is currently our choice because its metabolism, owing to spontaneous Hoffman's reaction and non-specific plasma esterases, is independent of the liver. ${ }^{44}$ Muscle relaxants do not affect hepatic blood flow. ${ }^{18}$

\section{Local anaesthetics}

Severe liver disease reduces both the metabolism of the 
amide class of local anaesthetics and the plasma concentration of alpha 1 -glycoprotein and albumin, thus exposing the patient to increased total and free plasma local anaesthetic agent concentrations. ${ }^{50}$ This should be borne in mind when repeated injections or continuous infusions of local anaesthetics are used.

\section{Mild analgesics}

Paracetamol (acetaminophen) has been shown to accumulate in healthy children with fever after repeated doses over two to three days. ${ }^{51}$ However, this accumulation did not result in increased transaminase levels or hepatotoxicity. It thus appears that usual doses of paracetamol $\left(60-80 \mathrm{mg} \cdot \mathrm{kg}^{-1} \cdot \mathrm{d}^{-1}\right)$ may be used for a short time in children with stable liver disease. On the contrary, nonsteroidal anti-inflammatory drugs (NSAIDs) which are eliminated by hepatic bio-transformation, should be used very cautiously because pre-existing liver disease may alter their metabolism and protein binding thus exposing the patient to an increased fraction of free drug. Moreover, NSAIDs inhibit platelet function, may cause gastrointestinal bleeding and a few cases of hepatotoxicity have been reported. Last, their risk of renal toxicity is enhanced in the presence of hypovolaemia, cirrhosis, nephrotoxic antibiotics or concurrent diuretic therapy. ${ }^{52}$ Known risk factors and drug side effects should thus be carefully evaluated before administering NSAIDs to children with stable PFIC.

To conclude, in our series of 22 children with PFIC, different anaesthetic agents were used without overt problems. When selecting the drugs to be administered to a child with PFIC, one should first consider the clinical stage of the disease: in addition to the usual preoperative paediatric examination, hepatic function and nutritional status should be carefully evaluated. Moreover, children presenting signs of portal hypertension should undergo systematic screening for hypoxaemia which could be due to pulmonary arteriovenous shunting. In all cases, anaesthetic agents with no or minimal hepatotoxicity should be used to avoid further deterioration of liver function. In the presence of decompensated liver disease (hypoalbuminaemia, prolonged prothrombin time, ascites and/ or encephalopathy), the dose of these agents should be titrated to the patient's response, bearing in mind that hypoalbuminaemia reduces the protein binding of most intravenous agents. The choice of anaesthetic agent should then be tailored to the type and duration of the planned procedure.

\section{Acknowledgements}

The authors gratefully acknowledge the critical review of this paper by Profs. P.L. Baele and J.L. Scholtes.

\section{References}

1 Linarelli LG, Williams CN, Phillips MJ. Byler's disease: fatal intrahepatic cholestasis. J Pediatr 1972; 81: 484-92.

2 Riely CA. Familial intrahepatic cholestatic syndromes. Semin Liver Dis 1987; 7: 119-33.

3 Odièvre $M$, Hadchouel $M$, Landrieu P, Alagille $D$, Eliot $N$. Long-term prognosis for infants with intrahepatic cholestasis and patent extrahepatic biliary tract. Arch Dis Child 1981; 56: 373-6.

4 Soubrane $O$, Gauthier F, DeVictor D, et al. Orthotopic liver transplantation for Byler's disease. Transplantation 1990; 50: 804-6.

5 Otte $J-B$, de Ville de Goyet J, Reding $R$, et al. Liver transplantation in children. In: Buts J-P, Sokal EM (Eds.). Management of Digestive and Liver Disorders in Infants and Children. Amstendam: Elsevier, 1993; 669-77.

6 Carlier $M$, van Obbergh $L$, Veyckemans $F$, et al. Intraoperative hemodynamic modifications during pediatric orthotopic liver transplantation. Intensive Care Med 1989; 15: S73-5.

7 Clayton RJ, Iber FL, Reubner BH, McKusick VA. Byler's disease: fatal familial intrahepatic cholestasis in an Amish kindred. J Pediatr 1965; 67: 1025-8.

8 Jacquemin E, Dumont $M$, Bernard $O$, Erlinger $S$, Hadchouel $M$. Evidence for defective primary bile acid secretion in children with progressive familial intrahepatic cholestasis (Byler disease). Eur J Pediatr 1994; 153: 424-8.

9 Whitington PF, Freese DK, Alonso EM, Schwarzenberg SJ, Sharp $H L$. Clinical and biochemical findings in progressive familial intrahepatic cholestasis. J Pediatr Gastroenterol Nutr 1994; 18: 134-41.

10 Sokal EM. Nutritional and medical care in chronic cholestasis. In: Buts J-P, Sokal EM (Eds.). Management of Digestive Liver Disorders in Infants and Children. Amsterdam: Elsevier, 1993; 537-42.

11 Barbé T, Losay J, Grimon G, et al. Pulmonary arteriovenous shunting in children with liver disease. J Pediatr 1995; 126: 571-9.

12 Jacquemin E, Setchell KDR, O'Connell NC, et al. A new cause of progressive intrahepatic cholestasis: $3 \beta$-hydroxy$\mathrm{C}_{2 T}$ steroid dehydrogenase/isomerase deficiency. $J$ Pediatr 1994; 125: 379-84.

13 Lachaux A, Loras-Duclawx I, Bouvier R, Dumontet $C$, Hermier $M$. Benign recurrent cholestasis with normal gamma-glutamyl-transpeptidase activity. J Pediatr 1992; 121: 78-80.

14 Clayton RJ, Iber FL, Ruebner BH, McKusick VA. Byler disease. Fatal familial intrahepatic cholestasis in an Amish kindred. American Joumal of Diseases in Children 1969; 117: 112-24.

15 Whitington PF, Whitington GL. Partial external diversion of bile for the treatment of intractable pruritus associated 
with intrahepatic cholestasis. Gastroenterology 1988; 95 : 130-6.

16 Veyckemans $F$, Baele P, Guillaume JE, Willems $E$, Robert $A$, Clerbaux $T$. Hyperbilirubinemia does not interfere with hemoglobin saturation measured by pulse oximetry. Anesthesiology 1989; 70: 118-22.

17 Silver MM, Bohn D, Shawn DH, et al. Association of pulmonary hypertension with congenital portal hypertension in a child. J Pediatr 1992; 120: 321-9.

18 Gelman S, Fernette $L$. Effects of anaesthetics on liver blood flow. In: Strunin L, Thomson S (Eds.). Baillière's Clinical Anesthesiology. The Liver and Anaesthesia. London: Baillière Tindall, 1992; 729-50.

19 Gelman S, Fowler $K C$, Smith $L R$. Liver circulation and function during isoflurane and halothane anesthesia. Anesthesiology 1984; 61: 726-30.

20 Ahlgren I, Aronsen F, Bjorkman I, Wetterlin S. The hemodynamic effect of halothane in the normovolemic dog. Acta Anaesthesiol Scand 1978; 22: 83-92.

21 Wark H, Earl J, Cooper M, Overton J. Halothane in children with chronic liver disease. Anaesth Intensive Care 1991; 19: 9-16.

22 Philipps AJ, Brimacombe JR, Simpson DL. Anaesthetic induction with isoflurane or halothane. Anaesthesia 1988; 43: 927-9.

23 Merin $R$, Bemard J-M, Doursout $M-F$, Cohen $M$, Chelly $J E$. Comparison of the effects of isoflurane and desflurane on cardiovascular dynamics and regional blood flow in the chronically instrumented dog. Anesthesiology 1991; 74: 568-72.

24 Bernard J-M, Doursout $M-F$, Wouters P, Hartley $C$, Merin R, Chelly JE. Effects of sevoflurane and isoflurane on hepatic circulation in the chronically instrumented dog. Anesthesiology 1992; 77: 541-5.

25 Patwardhan RV, Johnson RF, Hoyumpa A Jr, et al. Normal metabolism of morphine in cirrhosis. Gastroenterology 1981; 81: 1006-11.

26 Bower S, Sear JW, Roy RC, Carter RF. Effects of different hepatic pathologies on disposition of alfentanil in anaesthetized patients. $\mathrm{Br} \mathrm{J}$ Anaesth 1992; 68: 462-5.

27 Krishna DR, Klotz U. Extrahepatic metabolism of drugs in humans. Clin Pharmacokinet 1994; 26: 144-60.

28 Veroli P, O'Kelly B, Bertrand F, Trouvin JH, Farinotti $R$, Ecoffey $C$. Extrahepatic metabolism of propofol in man during the anhepatic phase of orthotopic liver transplantation. $\mathrm{Br} \mathrm{J}$ Anaesth 1992; 68: 183-6.

29 Janicki PK, James MFM, Erskine WAR. Propofol inhibits enzymatic degradation of alfentanil and sufentanil by isolated liver microsomes in vitro. Br J Anaesth 1992; 68: 311-2.

30 Shafer $S L$, Stanski $D R$. Improving the clinical utility of anesthetic drug pharmacokinetics (Editorial). Anesthesiology 1992; 76: 327-30.
31 Raoof $A A$, van Obbergh $L J$, Verbeeck $R K$. Propofol pharmacokinetics in children with biliary atresia. $\mathrm{Br} J$ Anaesth 1995; 74: 46-9.

32 Servin F, Desmonts JM, Haberer JP, Cockshott ID, Plummer GF, Farinotti $R$. Pharmacokinetics and protein binding of propofol in patients with cirrhosis. Anesthesiology 1988; 69: 887-91.

33 Van de Velde $M$, Wouters $P F$, Marcus A, Flameng $W$, Van Aken $H$. Effects of propofol on hepatic and renal perfusion in chronically instrumented dogs. Anesth Analg 1994; 78: $\mathrm{S} 451$.

34 Murray JM, Trinick TR. Hepatic function and indocyanine green clearance during and after prolonged anaesthesia with propofol. Br J Anaesth 1992; 69: 643-4.

35 Pandele G, Chaux F, Salvadori $C$, Duvaldestin P. Thiopental pharmacokinetics in patients with cirrhosis. Anesthesiology 1983; 59: 123-6.

36 Kay B. Ketamine. In: Kay B (Ed.). Total Intravenous Anesthesia. Amsterdam: Elsevier, 1991; 125-35.

37 van Beem $H$, Manger $F W$, van Boxtel $C$, van Benten $N$. Etomidate anaesthesia in patients with cirrhosis of the liver: pharmacokinetic data. Anaesthesia 1983; 38: 61-2.

38 Davis PJ, Stiller $R$, Cook DR, Brandom BW, Davis JE Scierka $A M$. Effects of cholestatic hepatic disease and chronic renal failure on alfentanil pharmacokinetics in children. Anesth Analg 1989; 68: 579-83.

39 Haberer JP, Schoeffler P, Couderc E, Duvaldestin P. Fentanyl pharmacokinetics in anaesthetized patients with cirrhosis. Br J Anaesth 1982; 54: 1267-9.

40 Chawvin M, Ferrier C, Haberer JP, et al. Sufentanil pharmacokinetics in patients with cirrhosis. Anesth Analg 1989; 68: 1-4.

41 Egan TD, Lemmens HJM, Fiset P, et al. The pharmacokinetics of the new short-acting opioid remifentanil (GI87084B) in healthy adult male volunteers. Anesthesiology 1993; 79: 881-92.

42 Shelly MP, Cory EP, Park GR. Pharmacokinetics of morphine in two children before and after liver transplantation. $\mathrm{Br} \mathrm{J}$ Anaesth 1986; 58: 1218-23.

43 Mazoit J-X, Sandouk P, Zetlaoui P, Scherrmann J-M. Pharmacokinetics of unchanged morphine in normal and cirrhotic subjects. Anesth Analg 1987; 66: 293-8.

44 Ward S, Neill EAM. Pharmacokinetics of atracurium in acute liver failure (with acute renal failure). $\mathrm{Br} \mathrm{J}$ Anaesth 1983; 55: 1169-72.

45 Whittaker $M$. Plasma cholinesterase variants and the anaesthetist. Anaesthesia 1980; 35: 174-97.

46 Duvaldestin P, Agoston S, Henzel E, Kersten UW, Desmonts JM. Pancuronium pharmacokinetics in patients with liver cirrhosis. $\mathrm{Br} \mathrm{J}$ Anaesth 1978; 50: 1131-6.

47 Lebrault $C$, Berger $J L$, D'Hollander AA, Gomeni $R$, Henzel $D$, Duvaldestin $P$. Pharmacokinetics and pharmaco- 
dynamics of vecuronium (ORG NC 45) in patients with cirrhosis. Anesthesiology 1985; 62: 601-5.

48 Cook DR, Freeman JR, Lai AA, et al. Pharmacokinetics of mivacurium in normal patients and in those with hepatic or renal failure. Br J Anaesth 1992; 69: 580-5.

49 Khalil M, D'Honneur G, Duvaldestin P, Slavov V, De Hys $C$, Gomeni $R$. Pharmacokinetics and pharmacodynamics of rocuronium in patients with cirrhosis. Anesthesiology 1994; 80: 1241-7.

50 Tucker GT, Mather LE. Properties, absorption, and disposition of local anesthetic agents. In: Cousins MJ, Bridenbaugh PO (Eds.). Neural Blockade in Clinical Anesthesia and Management of Pain, 2nd ed. Philadelphia: Lippincott, 1988; 47-111.

51 Nahata MC, Powell DA, Durrell DE, Miller MA. Acetaminophen accumulation in pediatric patients after repeated therapeutic doses. Eur J Clin Pharmacol 1984; 27: 57-9.

52 Lindsley $C B$. Uses of nonsteroidal anti-inflammatory drugs in pediatrics. American Journal of Diseases in Children 1993; 147: 229-36. 